\title{
Hybrid Radiation Modeling for Multi-phase Solar-thermal Reactor Systems Operated at High-temperature
}

\author{
Arto J. Groehn ${ }^{1}$, Allan Lewandowski ${ }^{2}$, Ronggui Yang ${ }^{3}$ and Alan W. Weimer ${ }^{1,4}$ \\ ${ }^{1}$ Department of Chemical and Biological Engineering, University of Colorado, Boulder, CO \\ 80303, United States. \\ ${ }^{2}$ Allan Lewandowski Solar Consulting LLC, Denver, CO 80206, United States. \\ ${ }^{3}$ Department of Mechanical Engineering, University of Colorado, Boulder, CO 80309, United \\ States. \\ Submitted to \\ Solar Energy \\ July, 2016 \\ ${ }^{4}$ Corresponding author: Tel: 303492 3759, alan.weimer@colorado.edu
}




\section{Abstract}

This work presents a method to couple ray-tracing and finite-volume radiation models at an arbitrary surface via both spatial and angular discretization. The interfacing algorithm is validated by comparing its results with full ray-tracing simulations of a compound parabolic concentrator as well as a large-scale solar-thermal reactor. The validated model is employed to investigate effects of silicon carbide tube radius on efficiency of ceria particle reduction for such applications as water or carbon dioxide splitting. Decreasing reactor tube radius from 25 to $5 \mathrm{~cm}$ reduced the total oxygen vacancy production rate from 3.7 to $0.3 \mathrm{kmol} / \mathrm{h}$ but nearly doubled the extent of ceria conversion when the particle bed velocity was maintained.

\section{Keywords}

Radiation modeling, multi-phase modeling, chemical reactions, solar-thermal energy. 


\section{Nomenclature}

\begin{tabular}{|c|c|}
\hline$\alpha$ & Volume fraction \\
\hline$a$ & Absorption coefficient \\
\hline$A_{\text {red }}$ & Pre-exponential factor for ceria reduction (720000 1/s) \\
\hline$A_{o x}$ & Pre-exponential factor for ceria oxidation $\left(82 \mathrm{~s}^{-1} \cdot \mathrm{bar}^{-0.218}\right)$ \\
\hline$\delta$ & Moles of oxygen vacancies per mole of cerium \\
\hline$E_{\text {red }}$ & Activation Energy for ceria reduction $(232 \mathrm{~kJ} / \mathrm{mol})$ \\
\hline$E_{o x}$ & Activation Energy for ceria oxidation $(36 \mathrm{~kJ} / \mathrm{mol})$ \\
\hline$\gamma$ & Lookout angle $\left({ }^{\circ}\right)$ \\
\hline$\Phi$ & Phase function \\
\hline$\vec{g}$ & Gravitational acceleration $\left(9.81 \mathrm{~m}^{2} / \mathrm{s}\right)$ \\
\hline$h$ & Specific species enthalpy $(\mathrm{kJ} / \mathrm{kg})$ \\
\hline$I$ & Radiation intensity (energy per area of emitting surface per unit solid angle) \\
\hline$J$ & Diffusion mass flux $\left(\mathrm{kg} \cdot \mathrm{m}^{-2} \cdot \mathrm{s}^{-1}\right)$ \\
\hline$K$ & Interphase momentum exchange coefficient \\
\hline$\dot{m}$ & Mass flow rate $(\mathrm{kg} / \mathrm{s})$ \\
\hline$n$ & Refractive index \\
\hline$\Omega^{\prime}$ & Solid angle \\
\hline$p$ & Pressure $(\mathrm{Pa})$ \\
\hline$\vec{q}$ & Heat flux $\left(\mathrm{W} / \mathrm{m}^{2}\right)$ \\
\hline$Q$ & Interphase heat exchange coefficient \\
\hline$\rho$ & Density $\left(\mathrm{kg} / \mathrm{m}^{3}\right)$ \\
\hline$\vec{r}$ & Position vector \\
\hline
\end{tabular}




\begin{tabular}{|c|c|}
\hline$R$ & Reaction rate $\left(\mathrm{kmol} \cdot \mathrm{m}^{-3} \cdot \mathrm{s}^{-1}\right)$ \\
\hline$R_{G}$ & Universal gas constant $\left(8.314 \mathrm{~J} \cdot \mathrm{K}^{-1} \cdot \mathrm{mol}^{-1}\right)$ \\
\hline$\sigma$ & Stefan-Boltzmann constant $\left(5.669 \cdot 10^{-8} \mathrm{~W} \cdot \mathrm{m}^{-2} \cdot \mathrm{K}^{-4}\right)$ \\
\hline$\sigma_{s}$ & Scattering coefficient \\
\hline$s$ & Path length \\
\hline$\vec{s}$ & Direction vector \\
\hline$S$ & Enthalpy source term due to reaction $\left(\mathrm{kJ} / \mathrm{m}^{3}\right)$ \\
\hline$\Theta$ & Acceptance angle $\left(^{\circ}\right)$ \\
\hline $\bar{\tau}$ & Stress tensor $(\mathrm{Pa})$ \\
\hline$t$ & Time (s) \\
\hline$T$ & Temperature (K) \\
\hline$\vec{v}$ & Velocity vector $(\mathrm{m} / \mathrm{s})$ \\
\hline $\mathrm{x}$ & Maxmium extent of ceria conversion $(0.35)$ \\
\hline$Y$ & Local mass fraction \\
\hline
\end{tabular}

\section{Subscripts}

$\begin{array}{ll}\text { Ce } & \text { Cerium } \\ i & \text { Species i } \\ g & \text { Gaseous phase } \\ p & \text { Phase } \mathrm{p} \\ q & \text { Phase } \mathrm{q} \\ s & \text { Solid phase } \\ v a c & \text { Oxygen vacancies }\end{array}$




\section{Introduction}

The objective of the present work is to facilitate the use of concentrated solar-thermal energy for such applications as gasification of carbonaceous solids (Piatkowski et al. 2011), carbothermal reduction of metal oxides (Murray et al. 1995), and water (Muhich et al. 2016) or carbon dioxide splitting by active redox particles, among others. At high temperatures required for these processes $(>1000 \mathrm{~K})$, radiation becomes an important heat transfer mechanism. Therefore, a computational model for solar-thermal reactor design and scale-up needs to interface radiative, convective and conductive heat transfer processes.

\subsection{Methods for Simulating Radiation}

Typical radiation models for engineering applications can be classified into Monte-Carlo/raytracing (MC/RT) and finite-volume (FV) based approaches. RT radiation models are based on tracing the paths of individual rays from a given source. By increasing the number of rays, the statistical error can be reduced below an arbitrary precision. Therefore, RT results are often considered as reference solutions for other methods (Howell 1998). Due to the high computational cost of tracing sufficient numbers of rays $\left(10^{5}-10^{8}\right)$, however, RT models are usually employed to solve radiation in static systems where effects of scattering, absorption and emission caused by moving particles or gases can be neglected as well as temperature-dependent and anisotropic material properties. In contrast, these effects are readily accounted for in FVbased radiation models that are per iteration computationally more efficient (Joseph et al. 2009). The accuracy obtained with FV-models is limited by the number of employed discrete solid angles as well as computational cells which result in ray-effect and false scattering errors, respectively (Martinek and Weimer 2013b). Above mentioned features makes RT methods suitable for heliostat fields while FV models are used mostly for chemical reactors and 
combustion chambers where iterative coupling with conductive and convective heat transfer is required.

Previously, He et al. (He et al. 2011) coupled RT and FV models to obtain 3-dimensional flow fields and temperature distributions for an absorbing tube used in a parabolic trough solarthermal power generator. The MC simulated surface heat flux through the outer surface of the absorber tube was then used as the input for the FV simulations. The model predicted tube outlet temperature agreed within $2 \%$ of experimental results.

Wirz et al. (Wirz et al. 2012) used an in-house MC code to compute the incident solar radiation for a parabolic trough solar concentrator. The temperature distributions at all relevant receiver surfaces were calculated by applying FV model for conduction as well as convection, and MC for thermal radiation, iteratively. Model predictions of heat losses, glass window temperatures and thermal efficiencies were consistent with experimental data.

To reduce computational cost without compromising the accuracy, a hybrid RT-FV radiation modeling scheme was suggested for a solar-thermal process by Martinek and Weimer (Martinek and Weimer 2013b). In this approach, the incoming specular reflections were solved with a RT code while a FV model was applied for the diffusive re-radiation away from the reactor walls. FV solutions were found to be least accurate when the reactor cavity was highly specular or the absorber area was minimized.

Recently, Moghimi et al. (Moghimi et al. 2015) compared FV and MC predictions of solar heat flux at an absorber tube surface for a linear Fresnel collector cavity receiver. Good agreement (error $<0.4 \%$ ) between the methods was obtained by sufficient mesh refinement and angular discretization accuracy.

Here, a method to couple RT and FV radiation models at an arbitrary surface by spatial and angular discretization of the RT input data is presented. The accuracy and optimal 
discretization level are evaluated by comparing the hybrid model predictions with those of the well-established and validated RT code SolTrace (Wendelin et al. 2013) for a secondary compound parabolic concentrator (CPC) as well as an industrial-scale reactor.

\subsection{Methods for Simulating Multi-phase Flows}

If reactive and moving particles are present in the solar-thermal reactor, the process model needs to account for heat, mass and momentum transfer within, as well as between, the fluid and solid phases. More information about heat transfer processes in particle beds can be found in the systematic review by Özgümüş (Özgümüş et al. 2013). The particles can be modelled either as discrete points (Lagrangian-approach) or as a continuum (Eulerian-approach) (Subramaniam 2013). In general, the discrete particle model is more accurate since the particle-particle interactions can be solved directly e.g. by discrete element methods. However, the source terms due to the particles at point locations can attain very high values causing non-linear behavior in the numerical solver (ANSYS 2015). The Eulerian approach is numerically more stable and efficient as only few additional transport equations need to be solved to account for the solidphase. Its disadvantage is the need for closure models to describe the particle-particle interactions (ANSYS 2015).

Meier (Meier 1999) investigated thermal decomposition of limestone $\left(\mathrm{CaCO}_{3}\right)$ in a solarthermal falling particle receiver. The multi-phase flow and convective heat transfer were solved by computational fluid dynamics (CFD) while a MC-method was employed to calculate particle heating by radiation. The Lagrangian particle transport model omitted effects of absorption and emission as well as chemical reactions. The falling particles could be heated up to $1200 \mathrm{~K}$, though particles smaller than $300 \mu \mathrm{m}$ were found to leave the reaction zone due to entrainment by 
convective air streams or contaminate the transparent window if one is used to enclose the reactor.

Chen et al. (Chen et al. 2006) conducted 3-D CFD simulations of multi-phase flow and heat transfer inside a falling particle solar receiver. Particles were modelled by a two-waycoupled Lagrangian method while a two-band FV-radiation model was employed to account for radiative heat transfer within the particles as well as their interaction with the receiver surfaces. Recirculation of hot exhaust gases was suggested to increase the absorber cavity efficiency.

Abanades et al. (Abanades et al. 2007) developed a CFD model to simulate the reduction of metal oxides for solar-thermal water splitting. The simulations accounted for multi-phase fluid flow, heat and mass transfer as well as zinc oxide dissociation. Lagrangian description was used for the particle-phase while the incoming solar flux was represented by a boundary condition in the CFD simulations. The model predicted increased zinc metal production rate as the absorber cavity diameter was decreased, consistent with experiments.

Thermal decomposition of $\mathrm{ZnO}$ was simulated also by Perkins and Weimer (Perkins and Weimer 2007) who solved the governing partial differential equations for momentum, energy, and mass transfer in a tubular solar receiver reactor using a finite element method. Uniform temperature profiles were attained regardless of the absorber tube diameter for the investigated small-scale systems. Increased oxidation rates near the tube walls suggested that novel methods need to be developed to increase material oxidation resistance at very high temperatures.

Martinek et al. investigated steam gasification of carbon with a 3-D steady state CFD model interfacing radiative, convective and conductive heat transfer (Martinek et al. 2012a) as well as fluid flow, mass transfer and chemical reactions (Martinek et al. 2012b). The absorbed solar energy profiles were solved with the MC method while a FV solver was utilized for the thermal re-radiation. Good agreement with experimentally measured temperatures (error <4 \%) 
was obtained, though transport of solar radiation was assumed to be decoupled from all other transport processes (Martinek et al. 2012a). Steam gasification of $42 \mathrm{~nm}$ acetylene black particles was simulated accounting for convection, Brownian motion and thermophoresis. Solar-tochemical efficiencies between 1-4\% were predicted for up to $9 \mathrm{~kW}$ of supplied solar power.

Here, reduction of $1 \mathrm{~mm}$ ceria $\left(\mathrm{CeO}_{2}\right)$ particles towards cerium $(\mathrm{Ce})$ metal is simulated using solar energy provided via the MC-FV interface, as shown in Figure 1. Ceria was selected as the exemplary material for investigation due to its relatively high oxygen ion conductivity and cyclability (Furler et al. 2012) as well as available reduction and oxidation kinetics that have been systematically validated (Bulfin et al. 2013).

\section{Theory}

\subsection{Flow and Radiation Model}

Since both laminar and turbulent flows are present simultaneously in the investigated reactor, the baseline (BSL) $k$ - $\omega$ model is used (Menter 1994). It was developed to blend the robust and accurate formulation of the $k-\omega$ model in near-wall region with the freestream independence of the $k-\varepsilon$ model in far field. In the CFD-solver, transport equations for $k$ and $\omega$ are solved in both particle and gas phase (ANSYS 2015).

Here, the FV-based discrete ordinates (DO) model (Chui and Raithby 1993) is employed to solve the radiative transfer equation 1 for a given number of discrete solid angles, represented by direction vectors $\vec{s}$, and coupled with the enthalpy transfer equation 3 via the source terms. The absorption and scattering due to the $\mathrm{CeO}_{2} / \mathrm{Ce}$ particles are included by the terms $a_{p}$ and $\sigma_{p}$, respectively. The absorption of radiation by gases is considered negligible for the investigated process. 


$$
\frac{\partial I(\vec{r}, \vec{s})}{\partial s}+\left(a+\sigma_{s}\right) I(\vec{r}, \vec{s})=\frac{a n^{2} \sigma T^{4}}{\pi}+\frac{\sigma_{s}}{4 \pi} \int_{0}^{4 \pi} I\left(\vec{r}, \vec{s}^{\prime}\right) \Phi\left(\vec{s} \cdot \vec{s}^{\prime}\right) \partial \Omega^{\prime}
$$

Figure 2 shows a schematic of the developed interfacing algorithm which reads RT data as the input, conducts spatial and angular discretization with selected accuracy and writes out the radiation flux source terms (eq. 1) in form of user-defined functions (UDF) for ANSYS Fluent (ANSYS 2015). First, simulations were conducted to evaluate the heliostat-field design required to obtain optimal reaction temperature for the silicon carbide $(\mathrm{SiC})$ tubes (maximal operating temperature $\sim 1900 \mathrm{~K})$.

\subsection{Heliostat Field Design}

The concentrations required to achieve the maximal operating temperatures of $\sim 1900 \mathrm{~K}$ cannot be achived by central receiver systems without the use of secondary concentration. The reduction of heat losses by significantly increased concentration results in reasonable efficiency but comes

with some restrictions on the field design. The optimal method for secondary concentration is the CPC (Winston et al. 2005).

One defining parameter for a CPC is its acceptance angle, $\theta$. This is the half angle which both defines its field of view and its maximum concentration. When used in the central receiver configuration of this study a tradeoff exists between increasing $\theta$ for larger fields and decreasing $\theta$ for higher concentration. To increase field size, the CPC optical axis can be aimed at some positive angle from vertical (lookout angle, $\gamma$ ) but at some loss in performance. For a non-zero $\gamma$ the resulting boundary for the field shape is elliptical (heliostats are included if their central point is within the ellipse). A non-zero $\gamma$ also allows for convenient placement of the CPC at the 
exterior surface of a roughly cylindrical reactor and also allows for multiple fields surrounding the tower to increase total power (see Fig. 1 for a schematic view of the field layout).

An initial evaluative investigation was conducted to approximately optimize the overall efficiency of a field with a CPC assuming only blackbody $(\varepsilon=1)$ radiative heat losses from the CPC exit aperture. Table 1 lists the parameters that were obtained from this study, for a design point of latitude $35^{\circ} \mathrm{N}$, day of year 82, hour 10. Direct Normal Irradiance (DNI) of $1000 \mathrm{~W} / \mathrm{m}^{2}$ from sun was used for all simulations. The heliostat spacing and number was then varied iteratively to obtain the required $\mathrm{SiC}$ reactor tube surface temperature (1900 K).

Initially, the heliostats were packed tightly into the field in an offset rectangular array with spacing set to just prevent any overlap in their swing volume. Spacing in the E-W direction (for the $\mathrm{N}$ facing field) was increased and applied to all rows in the heliostat array. Spacing in the $\mathrm{N}-\mathrm{S}$ direction was increased in a non-linear approach to reduce shading and blocking losses. After several trials a smaller heliostat field size was found that resulted in the target reactor temperature. The number of heliostats in this smaller field is 564 with a total area of $9204 \mathrm{~m}^{2}$. The efficiency for this solar field is $76 \%$, which is calculated by dividing the total power delivered to a sphere surrounding the reactor by the maximum incident power on the heliostat field (total heliostat area times the DNI).

\subsection{Reactive Multi-phase Model}

Here, the multi-phase simulations are conducted by the two-fluid Eulerian-method where the conservation equations for mass, momentum and energy are solved for both fluid- and solidphases. Detailed description of the employed multi-phase model is given by Syamlal et al. (Syamlal et al. 1993). The mass balance (eq. 2) accounts for the chemical reaction of ceria via the source term $S_{q}$. The energy balance (eq. 3) is affected by pressure, stress and heat conduction 
while chemical reactions, radiation and phase change are implemented via the source term $S_{q}$. The interphase heat transfer is modelled here with the expression of Hughmark (Hughmark 1967) which combines correlations for low and high particle Reynolds numbers.

The momentum transfer for fluid and solid-phases (eq. 4 \& 5) includes the effects of pressure, friction and buoyancy as well as multiphase interactions. The drag, $K_{g s}$, solids pressure, $p_{s}$, collisional and kinetic viscosity, $\tau_{s}$, are accounted for as described by Syamlal et al. (Syamlal et al. 1993) while the expression from Schaeffer (Schaeffer 1987) is used for the frictional viscosity, $\tau_{s}$.

$$
\begin{aligned}
& \frac{\partial}{\partial t}\left(\alpha_{q} \rho_{q} Y_{q}^{i}\right)+\nabla \cdot\left(\alpha_{q} \rho_{q} \overrightarrow{v_{q}} Y_{q}^{i}\right)=-\nabla \cdot \alpha_{q} \overrightarrow{J_{q}^{i}}+\alpha_{q} R_{q}^{i}+\sum_{p=1}^{n}\left(\dot{m}_{p^{i} q^{i}}-\dot{m}_{q^{i} p^{i}}\right) \\
& \frac{\partial}{\partial t}\left(\alpha_{q} \rho_{q} h_{q}\right)+\nabla \cdot\left(\alpha_{q} \rho_{q} \overrightarrow{v_{q}} h_{q}\right)=\alpha_{q} \frac{\partial p_{q}}{\partial t}+\overline{\tau_{q}}: \nabla \overrightarrow{v_{q}}-\nabla \overrightarrow{q_{q}}+S_{q}+\sum_{p=1}^{n}\left(Q_{p q}+\dot{m}_{p q} h_{p q}-\dot{m}_{q p} h_{q p}\right) \\
& \frac{\partial}{\partial t}\left(\alpha_{g} \rho_{g} \overrightarrow{v_{g}}\right)+\nabla \cdot\left(\alpha_{g} \rho_{g} \overrightarrow{v_{g} v_{g}}\right)=-\alpha_{g} \nabla p+\nabla \cdot \overline{\tau_{g}}+\alpha_{g} \rho_{g} \vec{g}+K_{g s}\left(\overrightarrow{v_{s}}-\overrightarrow{v_{g}}\right)-\dot{m}_{g s} \overrightarrow{v_{g s}}+\dot{m}_{s g} \overrightarrow{v_{s g}} \\
& \frac{\partial}{\partial t}\left(\alpha_{s} \rho_{s} \overrightarrow{v_{s}}\right)+\nabla \cdot\left(\alpha_{s} \rho_{s} \overrightarrow{v_{s} v_{s}}\right)=-\alpha_{s} \nabla p-\nabla p_{s}+\nabla \cdot \overline{\tau_{s}}+\alpha_{s} \rho_{s} \vec{g}+K_{g s}\left(\overrightarrow{v_{g}}-\overrightarrow{v_{s}}\right)+\dot{m}_{g s} \overrightarrow{v_{g s}}-\dot{m}_{s g} \overrightarrow{v_{s g}}(5)
\end{aligned}
$$

Reduction and re-oxidation of ceria (eq. 6) are described here by an Arrhenius-type expression following Bulfin et al. (Bulfin et al. 2013), and implemented to ANSYS Fluent (ANSYS 2015) by an user-defined function. Each mole of decomposed ceria produces one mole of solid $\mathrm{Ce}$ and gaseous $\mathrm{O}_{2}$ while the reaction enthalpy is calculated from the standard enthalpies of formation of the constituent species. The extent of conversion is reported in terms of moles of oxygen vacancies per mole of cerium ( $\delta$, eq. 7). The maximum value, $x$, for $\delta$ is 0.35 . 


$$
\begin{aligned}
& \frac{\partial \delta}{\partial t}=(x-\delta) A_{r e d} e^{\left(\frac{-E_{r e d}}{R_{G} T}\right)}-\delta P_{O_{2}}^{0.218} A_{o x} e^{\left(\frac{-E_{o x}}{R_{G} T}\right)} \\
& \frac{\left[O_{v a c}\right]}{[C e]}=\delta ; \frac{\left[O_{C e}\right]}{[C e]}=x-\delta
\end{aligned}
$$

Figure 3 shows the boundary conditions and geometry of the solar-thermal reactor consisting of 6 reaction tubes positioned symmetrically with respect to the three secondary compound parabolic concentrators (CPC). Here in all cases, equations 2-6 are solved until steadystate, though transient simulations could be conducted as well without modifying the present model. The 3-D FV simulations are conducted by the phase-coupled SIMPLE pressure-velocity algorithm (Vasquez and Ivanov 2000) using $1 \cdot 10^{6}-2 \cdot 10^{6}$ mesh cells. All variables are solved with second order spatial discretization assuming incompressible and ideal gas-phase (ANSYS 2015). The ceria particles have a diameter of $1 \mathrm{~mm}$ and flow as a moving bed with constant solid volume fraction of 0.63 and axial velocity of $1 \mathrm{~cm} / \mathrm{s}$. For tube radii 5,15 and $25 \mathrm{~cm}$ this results in total ceria mass flow rates of 4.4, 43.0 and $121.0 \mathrm{t} / \mathrm{h}$, respectively. Gravity is included to account for buoyancy while pressure, temperature and velocity at the RT-FV boundary are set to $1 \mathrm{~atm}$, $300 \mathrm{~K}$ and $0 \mathrm{~m} / \mathrm{s}$, respectively. The material properties for structural solids, particles and gases are given at Tables 2,3 and 4 , respectively.

\section{Results and Discussion}

\subsection{Radiation Model Interface Validation}

To numerically validate the RT-FV interfacing method, parametric simulations were first conducted with the CPC only (Fig. 3 dashed lines). This allowed to rapidly evaluate how the 
spatial and angular discretization correlate with the total and peak errors by parametric simulations. In the second part, the selected optimal discretization accuracy was employed to compare RT and FV model predictions of the whole solar-thermal rector (Fig. 3 dotted lines). For both cases, the RT simulations include the heliostat-field and the target geometry.

The SolTrace simulated rays are mapped as source terms at the CPC inlet plane for the FV simulations while the RT and FV results are compared at the CPC outlet (see Fig. 3 dashed lines). Here, the CPC has an acceptance half angle of $35^{\circ}$. It is placed at height of $50 \mathrm{~m}$ pointing down at an angle of $49^{\circ}$ from the vertical axis. The CPC walls are defined to be perfectly specularly reflective. Emissivity of 0.05 was used for the validation simulations while the temperature dependent correlation from Table 2 was employed otherwise assuming no spectral dependency. Such conditions can be assumed to yield estimates close to the upper limit of the expected error since FV simulations are known to perform better with increasingly diffusive radiation (Martinek and Weimer 2013b). For validation simulations, $8.3 \cdot 10^{5}$ rays from a field of 3337 heliostats enter the CPC with total power of $2.26 \cdot 10^{7} \mathrm{~W}$.

In Figure 4, the RT predicted incident radiation intensity is compared with FV solutions employing angular discretization $\left(N_{d}\right)$ of 200 or 1800 directions with $1.3 \cdot 10^{6}$ or $2.0 \cdot 10^{6}$ mesh cells $\left(N_{c}\right)$. The directional and diffusive errors (ray effects and false scattering) can be reduced by increasing $N_{d}$ and $N_{c}$, respectively. FV simulations agree reasonably well with RT results for all investigated discretization accuracies, though diffusive errors cannot be fully removed even at the highest employed accuracy.

Errors interpolated from eleven FV simulations at conditions of Figure 4 are shown in Figure 5. For the total power (Figure 5a), error less than $15 \%$ can be attained by coarse $N_{d}$ and fine $N_{c}$ as well as fine $N_{d}$ and coarse $N_{c}$. To reduce the error in the peak flux (Figure 5b), fine $N_{c}$ discretization is required, though. Therefore, it is beneficial to run the FV simulations with 
relatively fine $N_{c}$ and coarse $N_{d}$ for example, meshes consisting of $1 \cdot 10^{6}-2 \cdot 10^{6}$ cells with 200 1800 discrete solid angles.

\subsection{Multi-phase Simulations with Industrial-Scale Reactor}

Figure 6 shows quantitative agreement between RT and FV simulated incident radiation at the surface of a reactor tube (radius $=25 \mathrm{~cm}$ ) when accounting for solar-radiation only (see Fig. 3 dotted lines). Here, $9.4 \cdot 10^{5}$ rays from a field of 564 heliostats enter the CPC with total power of $6.8 \cdot 10^{6} \mathrm{~W}$. Values given in brackets in Figure 3 are used for boundary conditions. Consistent surface-incident radiation profiles demonstrate the validity of the present RT-FV coupling method also for simulations with the complete reactor geometry. The slight differences between the models are of similar magnitude as seen for the CPC only when using similar discretization accuracies (see Fig. 5). RT and FV predictions of the total radiative power on the reactor tube agreed rather well $\left(4.73 \cdot 10^{5}\right.$ and $4.69 \cdot 10^{5} \mathrm{~W}$, respectively). Likely due to diffusive errors (Martinek and Weimer 2013b), the FV model over predicted the surface incident radiation at negative height-coordinates, while on the upper half of the reactor tube FV model showed less radiation than the $\mathrm{RT}$ simulations.

The surface incident radiation profiles for the secondary concentrators and the reactor cavity are shown in Figure 7, accounting for a) direct solar radiation only and b) thermal reradiation as well at conditions of Figure 6. In Figure 7a, direct solar radiation is simulated by setting the temperature of the whole simulation domain to $1 \mathrm{~K}$, thus preventing thermal reradiation. In this case, highest surface incident flux of approximately $5 \cdot 10^{5} \mathrm{~W} / \mathrm{m}^{2}$ is observed around the CPC exit. When the reactor is allowed to heat up, by accounting also for conductive and convective hear transfer (Fig 7b), rather uniform surface incident flux of approximately $6 \cdot 10^{5}$ 
$\mathrm{W} / \mathrm{m}^{2}$ is present at the walls of the reactor cavity while peak flux of $7 \cdot 10^{5} \mathrm{~W} / \mathrm{m}^{2}$ is observed at the $\mathrm{SiC}$ tube surfaces.

In bottom row of Figure 7, cross-sections of incident radiation profiles are shown without (left) and with (right) thermal re-radiation. Here the incident radiation (Fig 7, bottom row) is defined as a volumetric quantity giving the total radiant load passing through the cell (in all directions), whereas surface incident radiation (Fig 7, top row) is the total radiant load hitting the surface (which will subsequently be absorbed, transmitted and reflected). Before implementing presented technology for solar-thermal processes regions of high radiation intensity (>5 X sun) should be shielded mechanically, optically, acoustically, etc. to prevent damage to birds, airplane pilots and employees, among other hazards.

Figure 8 shows a) reflected, b) absorbed and c) total radiation flux along with d) total heat flux accounting for convection and conduction for reactor tube radius of $25 \mathrm{~cm}$ at the conditions of Figure 6. The highest reflected radiation fluxes are observed around the CPC outlets while the diffusively reflective reactor cavity homogenizes radiation effectively. Here, reactor tubes absorb most energy by thermal radiation (see Fig. 7a \& b) though the highest flux intensities are caused by direct solar radiation from the CPCs.

The total radiative heat flux through the cavity wall is $2.37 \cdot 10^{5} \mathrm{~W}$ while due to convection and conduction back into the cavity the total heat loss is reduced to $5.39 \cdot 10^{4} \mathrm{~W}$. Maintaining the silver surfaces of the three CPCs at $473 \mathrm{~K}$ by cooling water causes total radiative heat loss of $1.99 \cdot 10^{5} \mathrm{~W}$ but again conductive and convective heat fluxes into the CPC cavity reduce the total heat loss to $1.66 \cdot 10^{5} \mathrm{~W}$. For the combined six reactor tubes, total radiative flux and heat flux are $9.03 \cdot 10^{5}$ and $7.91 \cdot 10^{5} \mathrm{~W}$. These results suggest that it may be beneficial to reduce the concentration of radiation inside the CPCs which may further help to mitigate problems caused by thermal stresses. 
Figure 9 presents FV simulated a) velocity and b) temperature profiles for a reactor tube radius of 5, 15 and $25 \mathrm{~cm}$ using the boundary conditions given in Figure 3. Similar flow pattern develops around, as well as inside, the reactor regardless of the $\mathrm{SiC}$ tube size. Highest gas velocities ( $2 \mathrm{~m} / \mathrm{s})$ are observed above the CPC inlet due to the heating of the outside reactor wall there by the rays that missed the CPC.

Radiation from the heliostat field is most concentrated at the CPC exits (see Fig. 7b) while the highest heat losses take place through the top of the reactor. Formation of recirculation zones inside the CPC's and the reactor cavity aids to reduce temperature gradients (Fig 9a), though convective losses from reactor cavity are effectively suppressed by the low gas velocity. Thereby, rather uniform reactor cavity wall and tube wall temperatures ( 1900 K) could be attained with adequate insulation for all cases, as shown in Figure 9b. This is an important design feature since it reduces thermal stress in the reactor tubes. However, as the tube radius is increased, the average reactor temperature decreases slightly due to the larger available surface area for heat transfer onto the reactive particle bed.

Figure 10. presents a) temperature, b) ceria reaction rate, c) oxygen mass fraction and d) ceria conversion $(\delta$, see eq. 6$)$ inside the reactor tubes. Increasing the $\mathrm{SiC}$ tube radius from 5 to $25 \mathrm{~cm}$ decreases the maximum particle bed temperature from 1890 to $1800 \mathrm{~K}$ while the average temperatures decreases from 1860 to $1690 \mathrm{~K}$. For tube radius of $15 \mathrm{~cm}$, the maximum and average bed temperature are 1860 and $1785 \mathrm{~K}$, respectively. To obtain significant amounts of ceria conversion $(\delta>0.01)$ temperatures above $\sim 1700 \mathrm{~K}$ were required experimentally (Scheffe et al. 2014). The gas-phase temperature profiles here were found not to differ significantly from those of the particles.

For all cases, ceria particle reduction rate is most rapid at the top of the reactor tubes, while a small amount of oxidation takes place near the bottom outlet due to the lower gas 
temperature there. For tube outer radii 5,15 and $25 \mathrm{~cm}$, the average reaction rates of $0.3,0.2$ and $0.13 \mathrm{~mol} \cdot \mathrm{m}^{-3} \cdot \mathrm{s}^{-1}$ are observed, respectively. Due to the slowest reaction rates at the tube with a 25 $\mathrm{cm}$ radius, less $\mathrm{O}_{2}$ is created from reduction of $\mathrm{CeO}_{2}$ and therefore the oxygen mass fraction does not reach unity at the top gas outlet. However, by employing lower vacuum pump pressure (currently $\Delta \mathrm{P}=-10^{\prime} 000 \mathrm{~Pa}$ ) pure oxygen might be collected also from the largest tubes. The pure nitrogen gas stream introduced from the reactor tube bottom increases the ceria conversion by decreasing the $\mathrm{O}_{2}$ partial pressure (Figure 10c), but also decreases reaction rate by lowering temperature (here gas inlet temperature is $1273 \mathrm{~K}$ ). Therefore the reaction is locally either inhibited or accelerated depending on the mixing of the $\mathrm{N}_{2}$ sheath gas and the hot product gases.

Ceria conversion $(\delta)$ follows the same overall trend as the reaction rate due to the enhanced heat transfer into the smaller tubes. Outlet conversions for tube radii 5,15 and $25 \mathrm{~cm}$ are $1.2 \cdot 10^{-2}, 8.6 \cdot 10^{-3}$ and $5.2 \cdot 10^{-3}$ which result in total oxygen vacancy production rates of 0.3 , 2.2 and $3.7 \mathrm{kmol} / \mathrm{h}$, respectively. The chemical reactor efficiencies for these tube radii are $0.7,4.8$ and $8.2 \%$. Here, the efficiency is calculated by dividing the chemical energy stored in reduced ceria by the energy provided to the reactor $(6.8 \mathrm{MW})$.In case the reduced ceria particles were circulated to be used for water splitting, the corresponding $\mathrm{H}_{2}$ production rates at STP would be $7.1 \cdot 10^{3}, 4.8 \cdot 10^{4}$ and $8.3 \cdot 10^{4} \mathrm{l} / \mathrm{h}$, assuming that complete reverse oxidation could be attained.

\section{Conclusions}

In this work, a method to couple RT and FV radiation models at an arbitrary surface via both spatial and angular discretization is developed and then employed to simulate an exemplary solarthermal process of ceria reduction. The validity of the solution is confirmed by comparing FV results with those of full RT simulation. Increasing ray directional discretization from 200 to 800 solid angles resulted in only a minor improvement for the investigated solar-thermal reactor 
geometry. Sufficient thermal insulation may be more important for high-temperature processes than geometry of the reactor cavity since thermal re-radiation homogenizes temperatures rather effectively as reported previously by Martinek and Weimer (Martinek and Weimer 2013a).

Despite the relatively low $\mathrm{CeO}_{2}$ conversion $\left(\delta=5.2 \cdot 10^{-3}\right)$ achieved for the largest reactor tubes (radius $25 \mathrm{~cm}$ ), total oxygen vacancy production rate of $3.7 \mathrm{kmol} / \mathrm{h}$ is obtained in the simulations with only solar energy. Decreasing the $\mathrm{SiC}$ tube radius to $5 \mathrm{~cm}$ enhances the heat transfer significantly, which results in increased ceria conversion $\left(\delta=1.2 \cdot 10^{-2}\right)$ but reduced overall production rate $(0.3 \mathrm{kmol} / \mathrm{h})$, when the bed velocity is maintained at $1 \mathrm{~cm} / \mathrm{s}$.

\section{Acknowledgements}

The research leading to these results has received funding from the Swiss National Science Foundation project no. P2EZP2_155574, the Department of Energy Advanced Research Program Agency - Energy (ARPA-E) Award AR0000404 and from grant DE-EE0006671 from the U.S. Department of Energy Office of Energy Efficiency and Renewable Energy (EERE). 


\section{Tables \& Figures}

Table 1. Initial evaluation study parameters

\begin{tabular}{|c|c|}
\hline Parameter & Value \\
\hline Tower height (at CPC entrance) & $75 \mathrm{~m}$ \\
\hline CPC acceptance angle $(\theta)$ & $30^{\circ}$ \\
\hline $\mathrm{CPC}$ entrance diameter & $3.0 \mathrm{~m}$ \\
\hline CPC exit diameter & $1.52 \mathrm{~m}$ \\
\hline CPC height (truncated to 0.8 of full) & $3.16 \mathrm{~m}$ \\
\hline CPC concentration & 3.9 \\
\hline CPC lookout angle $(\gamma)$ & $44.5^{\circ}$ \\
\hline Heliostat size & $4 \times 4 \mathrm{~m}$ square \\
\hline $\begin{array}{l}\text { Heliostat focal lengths } \\
\text { (spherical curvature) }\end{array}$ & $\begin{array}{c}112 \mathrm{~m}, 179 \mathrm{~m}, 246 \mathrm{~m} \\
\text { (based on location within field) }\end{array}$ \\
\hline Number of fields & $3\left(0^{\circ}, 120^{\circ}, 240^{\circ}\right.$ from true $\left.\mathrm{N}\right)$ \\
\hline Number of heliostats & 2814 \\
\hline Total heliostat field size & $45024 \mathrm{~m}^{2}$ \\
\hline Direct Normal Irradiance & $1000 \mathrm{~W} / \mathrm{m}^{2}$ \\
\hline Sunshape & CSR10 (Neumann et al. 2002) \\
\hline Design point parameters & Lat $35^{\circ} \mathrm{N}$, Day 82 , Hour 10 \\
\hline
\end{tabular}


Table 2. Thermodynamic properties for solid materials.

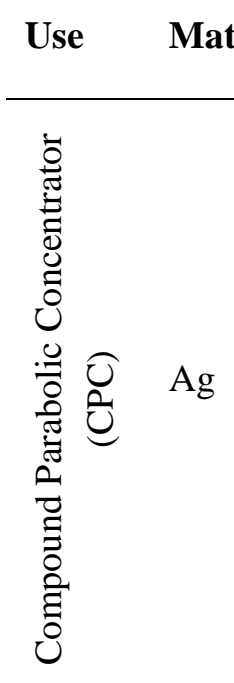

Expression

$\begin{array}{lll}\text { (DIPPR 2005) Density, } \mathrm{kg} \cdot \mathrm{m}^{-3} & 10490 & 298\end{array}$

\begin{tabular}{llc}
\hline (DIPPR 2005) Thermal & $436.13-0.011922 \cdot \mathrm{T}-0.000084465 \cdot \mathrm{T}^{2}$ & $100-1234$ \\
conductivity, $\mathrm{W} \cdot \mathrm{m}^{-1} \cdot \mathrm{K}^{-1}$ & $+0.000000033463 \cdot \mathrm{T}^{3}$ & \\
\hline (DIPPR 2005) Heat capacity, & $\left(24710+1.14 \cdot \mathrm{T}+0.00388 \cdot \mathrm{T}^{2}\right) / 107.8682$ & $298-1234$ \\
$\mathrm{~J} \cdot \mathrm{kg}^{-1} \cdot \mathrm{K}^{-1}$ & & $283-973$ \\
\hline Ramanathan et al. 1977) & $-0.002293+6.523 \cdot 10^{-5} \cdot \mathrm{T}-5.993 \cdot 10^{-8} \cdot \mathrm{T}^{2}$ & \\
Emissivity & $+2.306 \cdot 10^{-11} \cdot \mathrm{T}^{3}$ & \\
\hline Diffusively reflected fraction & 0 &
\end{tabular}

Molecular weight, $\mathrm{g} \cdot \mathrm{mol}^{-1} \quad 107.8682$

(RATH 2016) Density, $\mathrm{kg} \cdot \mathrm{m}^{-3} \quad 400$

293

\begin{tabular}{llc}
\hline Fit based on (RATH 2016) & $5.2683 \cdot 10^{-2}+10^{-4} \cdot \mathrm{T}+4.0179 \cdot 10^{-8} \cdot \mathrm{T}^{2}$ & $673-1673$ \\
Thermal conductivity, $\mathrm{W} \cdot \mathrm{m}^{-1} \cdot \mathrm{K}^{-1}$ & & \\
\hline (NIST 2016a) Heat capacity, & $1000 \cdot\left(102.4290+38.74980 \cdot\left(\mathrm{T} / 10^{3}\right)-\right.$ & $298-2327$ \\
$\mathrm{~J} \cdot \mathrm{kg}^{-1} \cdot \mathrm{K}^{-1}$ & $15.91090 \cdot\left(\mathrm{T} / 10^{3}\right)^{2}+2.628181 \cdot\left(\mathrm{T} / 10^{3}\right)^{3}-$ & \\
\hline Fit based on (Morrell 1987) & $1.9386 \cdot 10^{-1}+2.3785 \cdot 10^{-3} \cdot \mathrm{T}-3.5505 \cdot 10^{-6} \cdot \mathrm{T}^{2}$ & $327-1745$ \\
Emissivity & $+1.8687 \cdot 10^{-9} \cdot \mathrm{T}^{3}-3.3109 \cdot 10^{-13} \cdot \mathrm{T}^{4}$ & \\
\hline Diffusively reflected fraction & 1 &
\end{tabular}

Molecular weight, $\mathrm{g} \cdot \mathrm{mol}^{-1} \quad 101.96$

$\begin{array}{lll}\text { (NIST 2016b) Density, } \mathrm{kg} \cdot \mathrm{m}^{-3} & 3160 & 293\end{array}$

Fit based on (Munro 1997) $\quad 1.8042 \cdot 10^{-2}-2.7570 \cdot 10^{-1} \cdot \mathrm{T}$

Thermal conductivity, $\mathrm{W} \cdot \mathrm{m}^{-1} \cdot \mathrm{K}^{-1} \quad+1.7908 \mathrm{e}-04 \cdot \mathrm{T}^{2}-4.1024 \cdot 10^{-8} \cdot \mathrm{T}^{3}$

\begin{tabular}{lll}
\hline Fit based on (Munro 1997) & $3.1993 \cdot 10^{2}+1.6189 \cdot \mathrm{T}-9.8838 \cdot 10^{-4} \cdot \mathrm{T}^{2}$ & $293-1773$
\end{tabular}

$\mathrm{SiC} \quad$ Heat capacity, $\mathrm{J} \cdot \mathrm{kg}^{-1} \cdot \mathrm{K}^{-1} \quad+2.2509 \cdot 10^{-7} \cdot \mathrm{T}^{3}$

Fit based on (Neuer and Jaroma- $\quad 7.4470 \cdot 10^{-1}+2.2013 \cdot 10^{-4} \cdot \mathrm{T}-5.5843 \cdot 10^{-8} \cdot \mathrm{T}^{2} \quad 1168-1714$

Weiland 1998) Emissivity

Diffusively reflected fraction

1

Molecular weight, $\mathrm{g} \cdot \mathrm{mol}^{-1} \quad 40.11$

$\mathbf{K}$

98

Temperature, 
Table 3. Thermodynamic properties for particle-phase species.

Use Material Property

Table 6-1 in (Furler 2014)

Density, $\mathrm{kg} \cdot \mathrm{m}^{-3}$

Table 6-1 in (Furler 2014)

Thermal conductivity, $\mathrm{W} \cdot \mathrm{m}^{-1} \cdot \mathrm{K}^{-1}$

$\left.\left.{ }^{6} \cdot \mathrm{T}^{2}+2.8 \cdot 10^{-9} \cdot \mathrm{T}^{3}\right)\right)$

Table 6-1 in (Furler 2014)

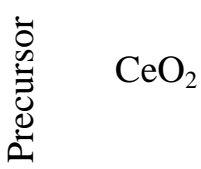

Heat capacity, $\mathrm{J} \cdot \mathrm{kg}^{-1} \cdot \mathrm{K}^{-1}$

(Yaws 2006) Enthalpy of formation, $\mathrm{J} \cdot \mathrm{kmol}^{-1}$

Table 6-1 in (Furler 2014)

Absorption coefficient, $\mathrm{m}^{-1}$

Table 6-1 in (Furler 2014)

Scattering coefficient, $\mathrm{m}^{-1}$

Molecular weight, $\mathrm{g} \cdot \mathrm{mol}^{-1}$

172.115

\section{Expression}

7220

$\left(\left(17.8004-0.02402 \cdot \mathrm{T}+0.0000112032 \cdot \mathrm{T}^{2}\right.\right.$

$\left.1.7 \cdot 10^{-9} \cdot \mathrm{T}^{3}\right) /\left(7.9799+0.00483384 \cdot \mathrm{T}-9.3397 \cdot 10^{-}\right.$

$0.0001271 \cdot \mathrm{T}^{2}+0.2697656 \cdot \mathrm{T}+299.8695684$

$-1.0887 \cdot 10^{9}$

$((1.0-(-0.00006 \cdot \mathrm{T}+0.411)) \cdot 367.0)$

$((-0.00006 \cdot T+0.411) \cdot 367.0)$

172.115
Temperature,

K

298

$280-2000$

280-1100

298

280-3000

280-3000

\begin{tabular}{|c|c|c|c|c|}
\hline \multirow{7}{*}{ 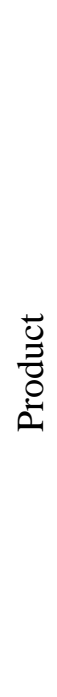 } & \multirow{7}{*}{$\mathrm{Ce}$} & (Knovel 2008) Density, $\mathrm{kg} \cdot \mathrm{m}^{-3}$ & 6670 & 298 \\
\hline & & $\begin{array}{l}\text { (Yaws } 2006 \text { ) Thermal } \\
\text { conductivity, } \mathrm{W} \cdot \mathrm{m}^{-1} \cdot \mathrm{K}^{-1}\end{array}$ & $\begin{array}{l}10^{\wedge}(1.00173-(27.6284 / \mathrm{T})+0.000545133 \cdot \mathrm{T} \\
\left.\left.\left.\left.-1.80778 \cdot 10^{-7} \cdot \mathrm{T}^{2}\right)\right)\right)\right)\end{array}$ & $100-1000$ \\
\hline & & $\begin{array}{l}\text { (Yaws 2011) Heat capacity, } \\
\mathrm{J} \cdot \mathrm{kg}^{-1} \cdot \mathrm{K}^{-1}\end{array}$ & $\begin{array}{l}1000 \cdot(39.88675-0.1732651 \cdot \mathrm{T}+0.0008284633 \\
\cdot \mathrm{T}^{2}-1.90217 \cdot 10^{-} \cdot \mathrm{T}^{3}+2.38308 \cdot 10^{-9} \cdot \mathrm{T}^{4} \\
\left.\left.\left.-1.53923 \cdot 10^{-12} \cdot \mathrm{T}^{5}\right)+4.00986 \cdot 10^{-16} \cdot \mathrm{T}^{6}\right)\right) / 140.116\end{array}$ & $298-1000$ \\
\hline & & Enthalpy of formation, $\mathrm{J} \cdot \mathrm{kmol}^{-1}$ & 0 & 298 \\
\hline & & $\begin{array}{l}\text { Table 6-1 in (Furler 2014) } \\
\text { Absorption coefficient, } \mathrm{m}^{-1}\end{array}$ & $((1.0-(-0.00006 \cdot \mathrm{T}+0.411)) \cdot 367.0)$ & $280-3000$ \\
\hline & & $\begin{array}{l}\text { Table 6-1 in (Furler 2014) } \\
\text { Scattering coefficient, } \mathrm{m}^{-1}\end{array}$ & $((-0.00006 \cdot \mathrm{T}+0.411) \cdot 367.0)$ & $280-3000$ \\
\hline & & Molecular weight, $\mathrm{g} \cdot \mathrm{mol}^{-1}$ & 140.116 & \\
\hline
\end{tabular}


Table 4. Thermodynamic properties for gas-phase species.

Polynomial values reported as $A_{1}+A_{2} T+A_{3} T^{2}+A_{4} T^{3}+A_{5} T^{4}$.

\begin{tabular}{|c|c|c|c|c|c|}
\hline Species & $\begin{array}{l}\text { Heat Capacity, } \\
\mathbf{J} \cdot \mathbf{k g}^{-1} \cdot \mathbf{K}^{-1}\end{array}$ & & $\begin{array}{l}\text { Thermal } \\
\text { Conductivity, } \\
\mathbf{W} \cdot \mathbf{m}^{-1} \cdot \mathbf{K}^{-1}\end{array}$ & $\begin{array}{l}\text { Viscosity, } \\
\mathbf{k g} \cdot \mathrm{m}^{-1} \cdot \mathrm{s}^{-1}\end{array}$ & $\begin{array}{l}\text { Enthalpy of } \\
\text { formation, } \\
\mathrm{J} / \mathrm{kmol}\end{array}$ \\
\hline \multirow{6}{*}{$\begin{array}{l}\text { (ANSYS } \\
2015) \\
\text { Nitrogen }\end{array}$} & $300 \mathrm{~K}>\mathrm{T}<1000 \mathrm{~K}:$ & $1000 \mathrm{~K} \geq T<5000 \mathrm{~K}$ & \multirow{6}{*}{$2.420 \cdot 10^{-2}$} & \multirow{6}{*}{$1.663 \cdot 10^{-5}$} & \multirow{6}{*}{0} \\
\hline & $A_{1}=9.790 \cdot 10^{2}$ & $\mathrm{~A}_{1}=8.686 \cdot 10^{2}$ & & & \\
\hline & $\mathrm{A}_{2}=4.179 \cdot 10^{-1}$ & $\mathrm{~A}_{2}=4.416 \cdot 10^{-1}$ & & & \\
\hline & $\mathrm{A}_{3}=-1.176 \cdot 10^{-3}$ & $A_{3}=-1.687 \cdot 10^{-4}$ & & & \\
\hline & $\mathrm{A}_{4}=1.674 \cdot 10^{-6}$ & $\mathrm{~A}_{4}=2.997 \cdot 10^{-8}$ & & & \\
\hline & $A_{5}=-7.256 \cdot 10^{-10}$ & $A_{5}=-2.004 \cdot 10^{-12}$ & & & \\
\hline \multirow{6}{*}{$\begin{array}{l}\text { (ANSYS } \\
2015) \\
\text { Oxygen }\end{array}$} & $300 \mathrm{~K}>\mathrm{T}<1000 \mathrm{~K}:$ & $1000 \mathrm{~K} \geq T<5000 \mathrm{~K}$ & \multirow{6}{*}{$2.460 \cdot 10^{-2}$} & \multirow{6}{*}{$1.919 \cdot 10^{-5}$} & \multirow{6}{*}{0} \\
\hline & $\mathrm{A}_{1}=8.348 \cdot 10^{2}$ & $A_{1}=9.607 \cdot 10^{2}$ & & & \\
\hline & $\mathrm{A}_{2}=2.930 \cdot 10^{-1}$ & $\mathrm{~A}_{2}=1.594 \cdot 10^{-1}$ & & & \\
\hline & $A_{3}=-1.496 \cdot 10^{-4}$ & $\mathrm{~A}_{3}=-3.271 \cdot 10^{-5}$ & & & \\
\hline & $\mathrm{A}_{4}=3.414 \cdot 10^{-7}$ & $\mathrm{~A}_{4}=4.613 \cdot 10^{-9}$ & & & \\
\hline & $\mathrm{A}_{5}=-2.278 \cdot 10^{-10}$ & $A_{5}=-2.953 \cdot 10^{-13}$ & & & \\
\hline
\end{tabular}




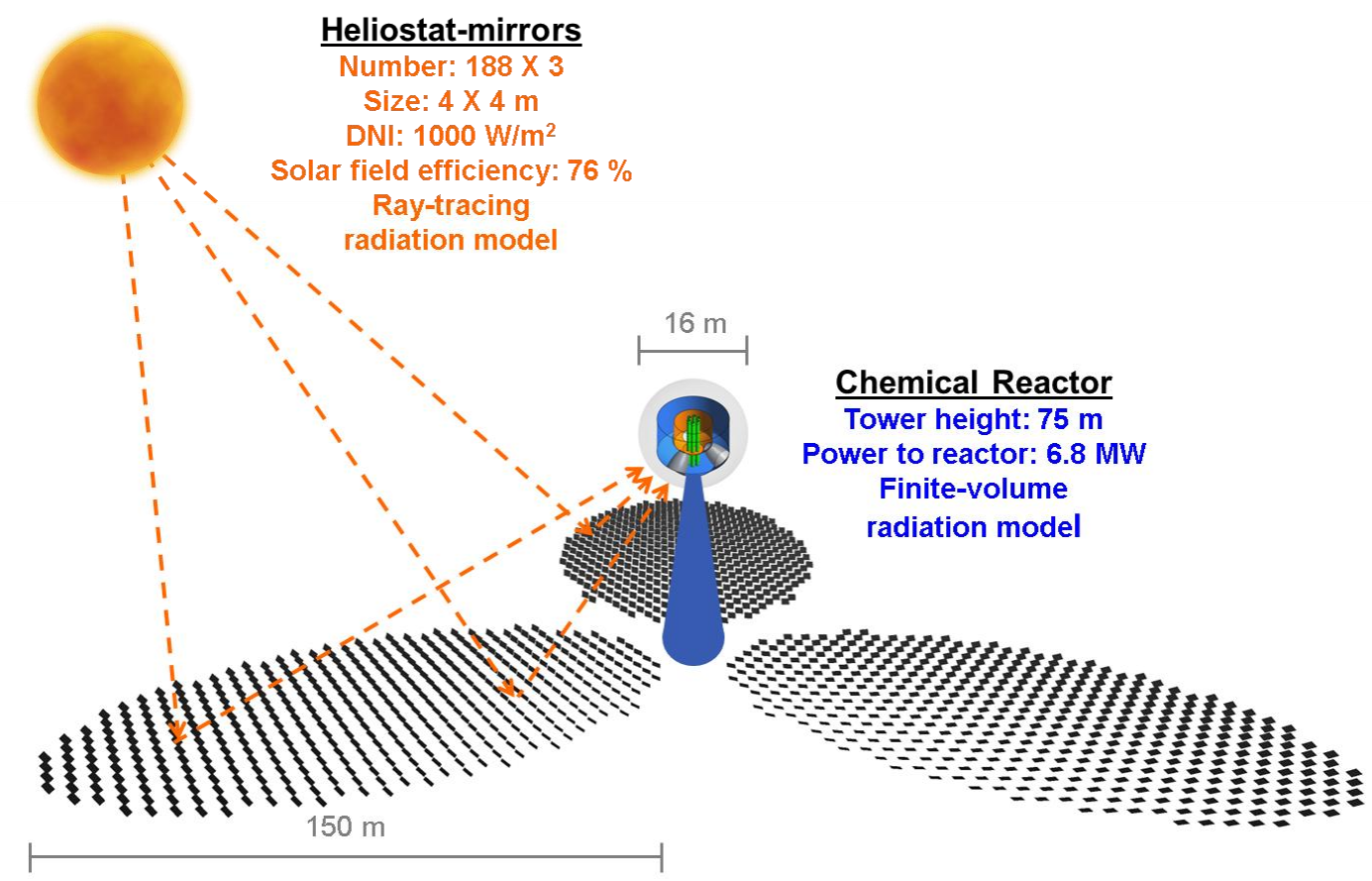

Figure 1. Schematic representation of the heliostat fields and the chemical reactor used in the simulations after matching the field size (power input) to the desired reactor temperature. The heliostat-fields and chemical reactor are simulated with RT and FV-based radiation models, respectively. 


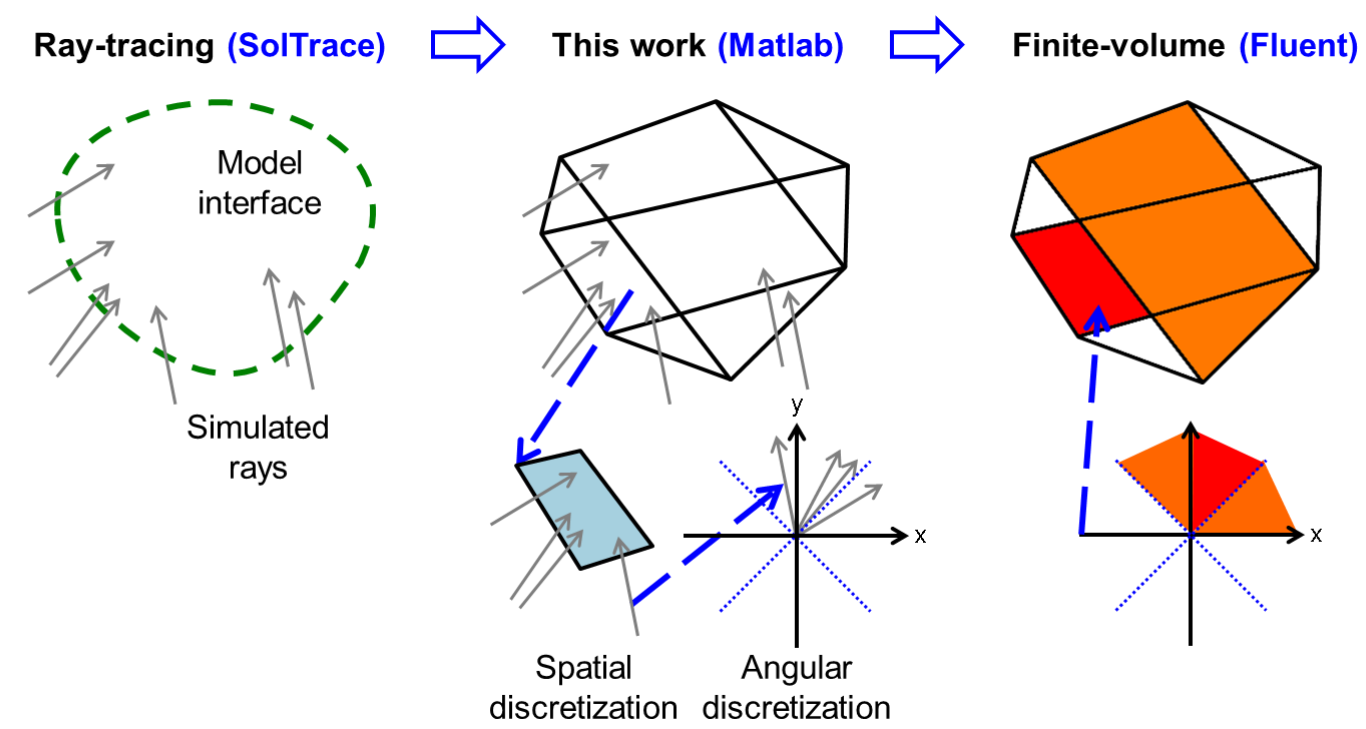

Figure 2. Interfacing of ray-tracing and finite-volume radiation models by spatial and angular discretization. Soltrace-simulated ray coordinates and directions at an arbitrary surface are classified into selected number of bins. The resulting solar energy fluxes per solid angle can be used as the source terms for the finite-volume radiation model. 


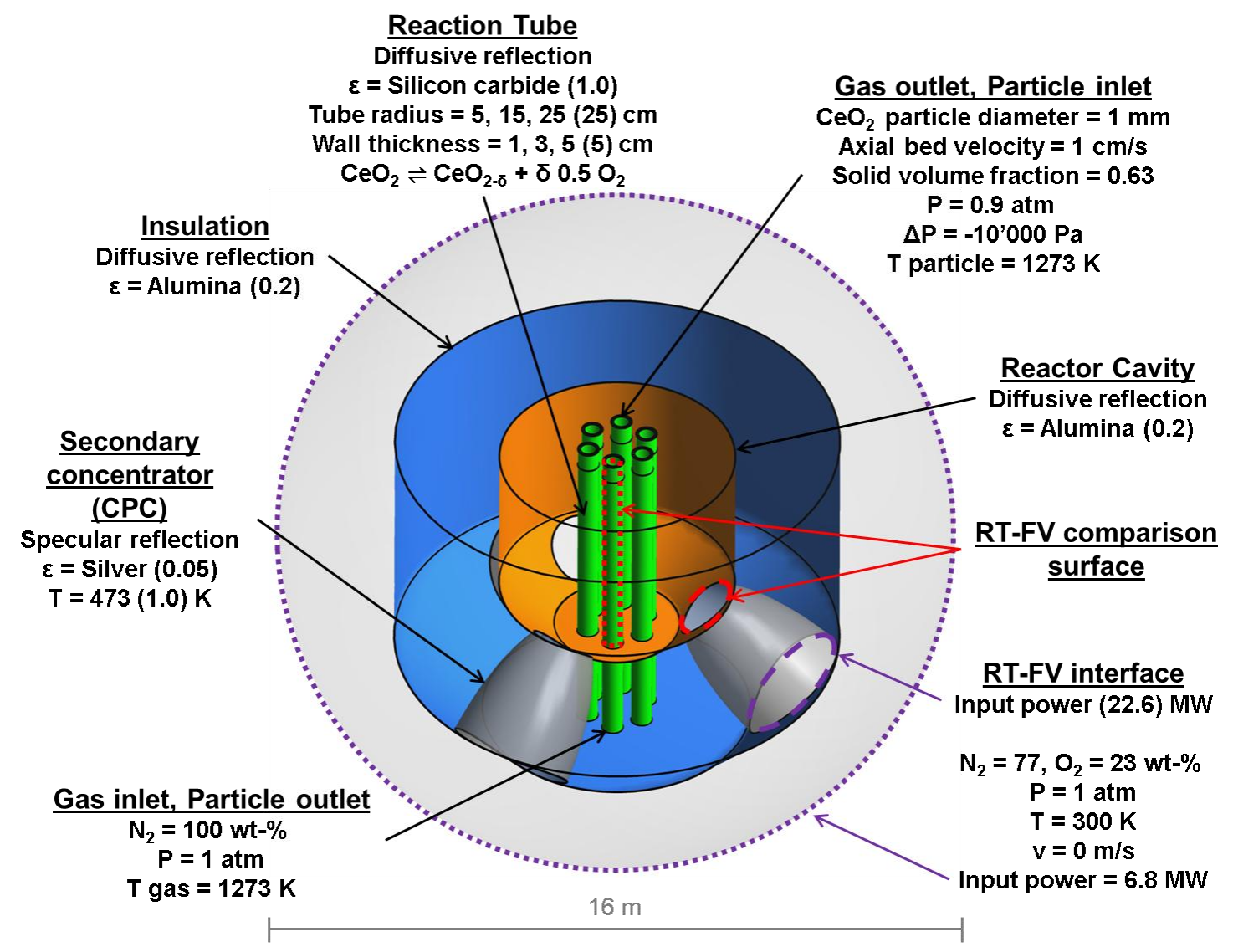

Figure 3. Geometry and boundary conditions for multiphase reactor simulations. Values used for validation of the RT-FV interfacing are given in brackets. Validation was conducted by simulating the CPC (dashed lines) and the complete reactor (dotted lines) with both radiation models and comparing their results at the CPC outlet (red dashed line) as well as the reaction tube surface (red dotted line), respectively. 


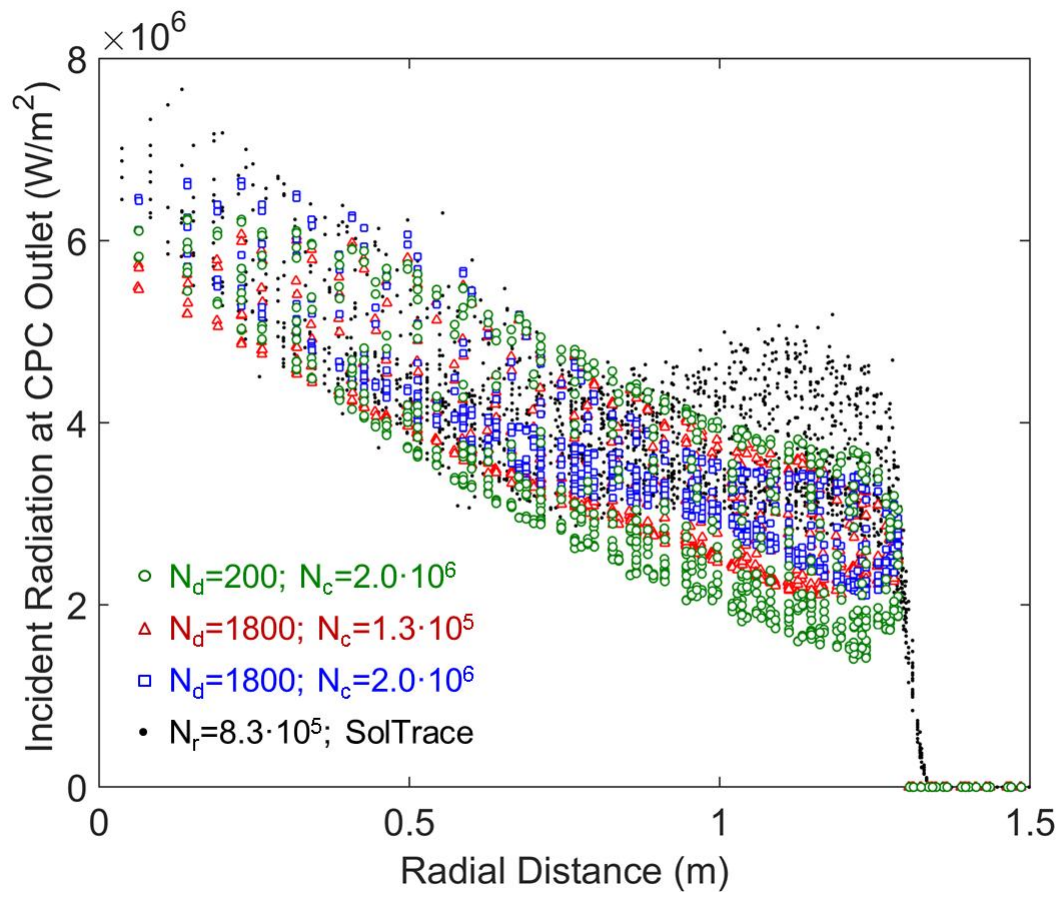

Figure 4. Comparison of ray-tracing and finite-volume model predicted surface incident radiation profiles at the outlet of the secondary concentrator for different spatial (number of cells, $\mathrm{N}_{\mathrm{c}}$ ) and angular (number of solid angles, $\mathrm{N}_{\mathrm{d}}$ ) discretization accuracies. In SolTrace, $8.3 \cdot 10^{5}$ rays (number of rays, $\mathrm{N}_{\mathrm{r}}$ ) were traced and their positions binned by the natural neighbor interpolation. 


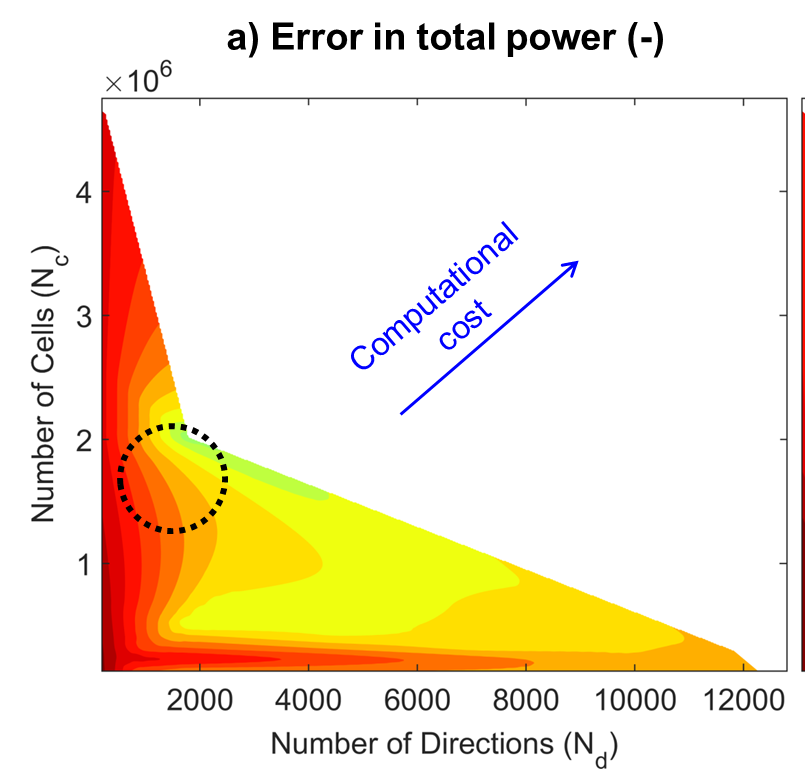

b) Error in peak flux (-)

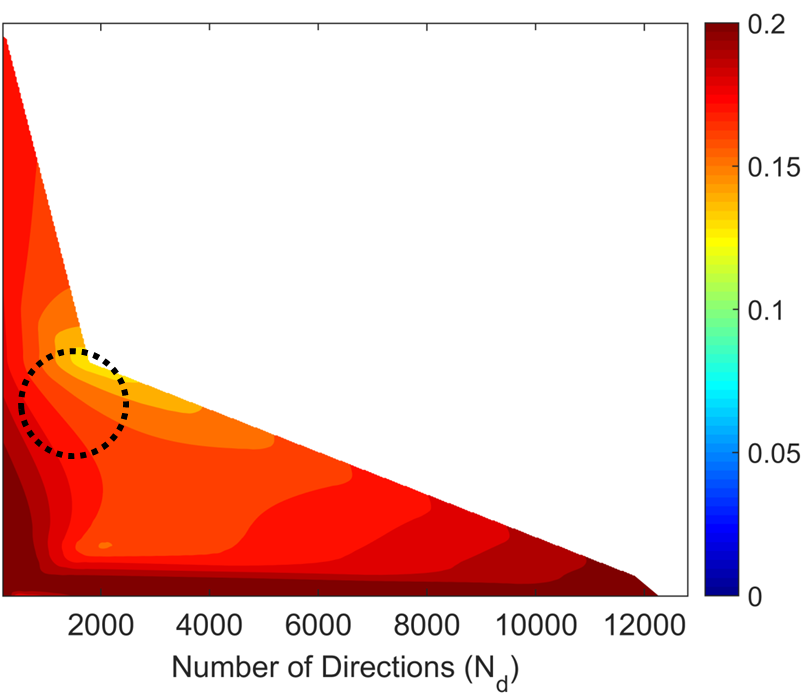

Figure 5. Interpolated relative errors in a) total radiative power and b) peak flux intensity for the finite-volume radiation model as a function of spatial and angular discretization accuracy. Both errors can be minimized by using high $N_{c}$ and low $N_{d}$ as indicated by the dashed circle. Interpolation is based on 11 simulations of the CPC. 


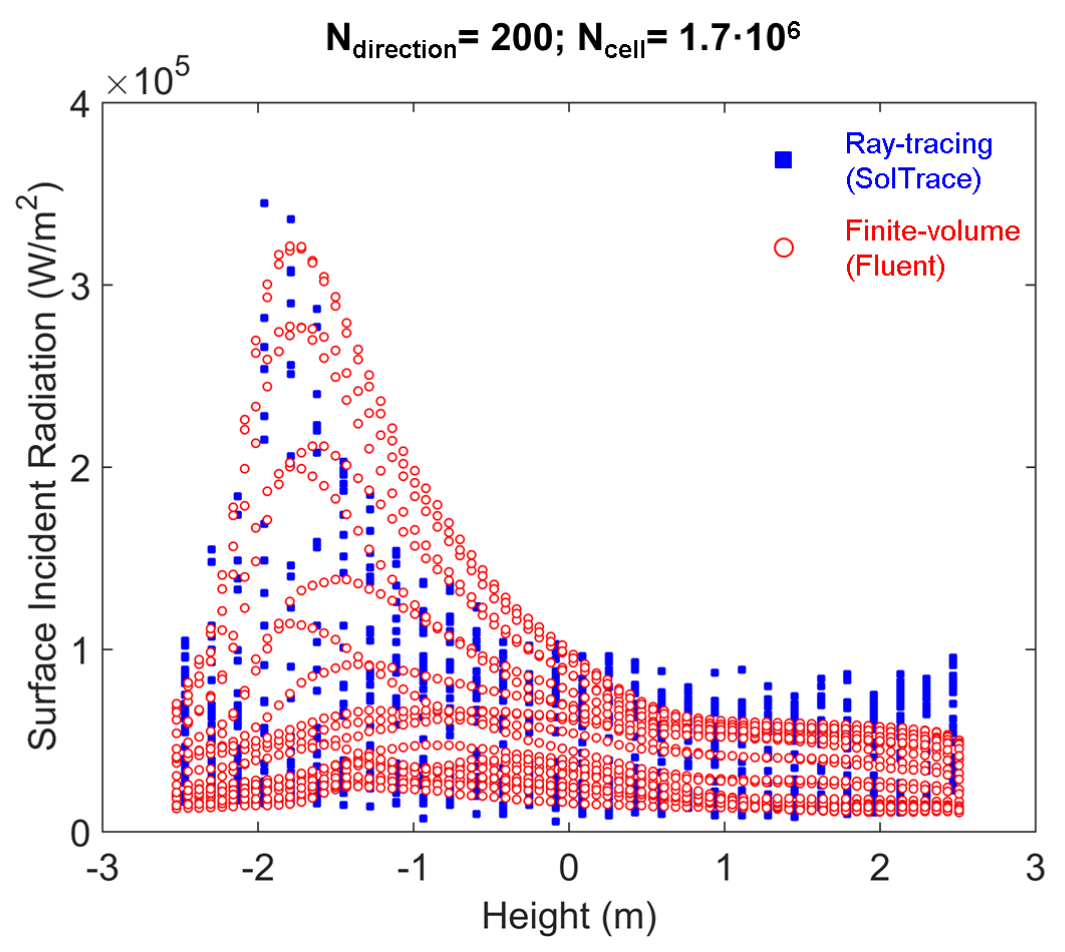

Figure 6. Comparison of RT and FV radiation model predicted surface incident radiation profiles along a single reactor tube. Radiation was simulated in the complete reactor geometry by both models. RT and FV predicted total radiative power on the reactor tube are $4.73 \cdot 10^{5}$ and $4.69 \cdot 10^{5}$ $\mathrm{W}$, respectively. RT predicted peak flux of $3.45 \cdot 10^{5} \mathrm{~W} / \mathrm{m}^{2}$ (uncertainty $+/-5 \%$ ) is $\sim 7 \%$ higher than that from the FV simulations $\left(3.21 \cdot 10^{5} \mathrm{~W} / \mathrm{m}^{2}\right)$. Both the height and azimuthal coordinates are divided into 30 bins to present the SolTrace data. 


\section{$\begin{array}{lll}\text { a) Solar radiation } & \text { b) Solar and thermal radiation }\end{array}$}
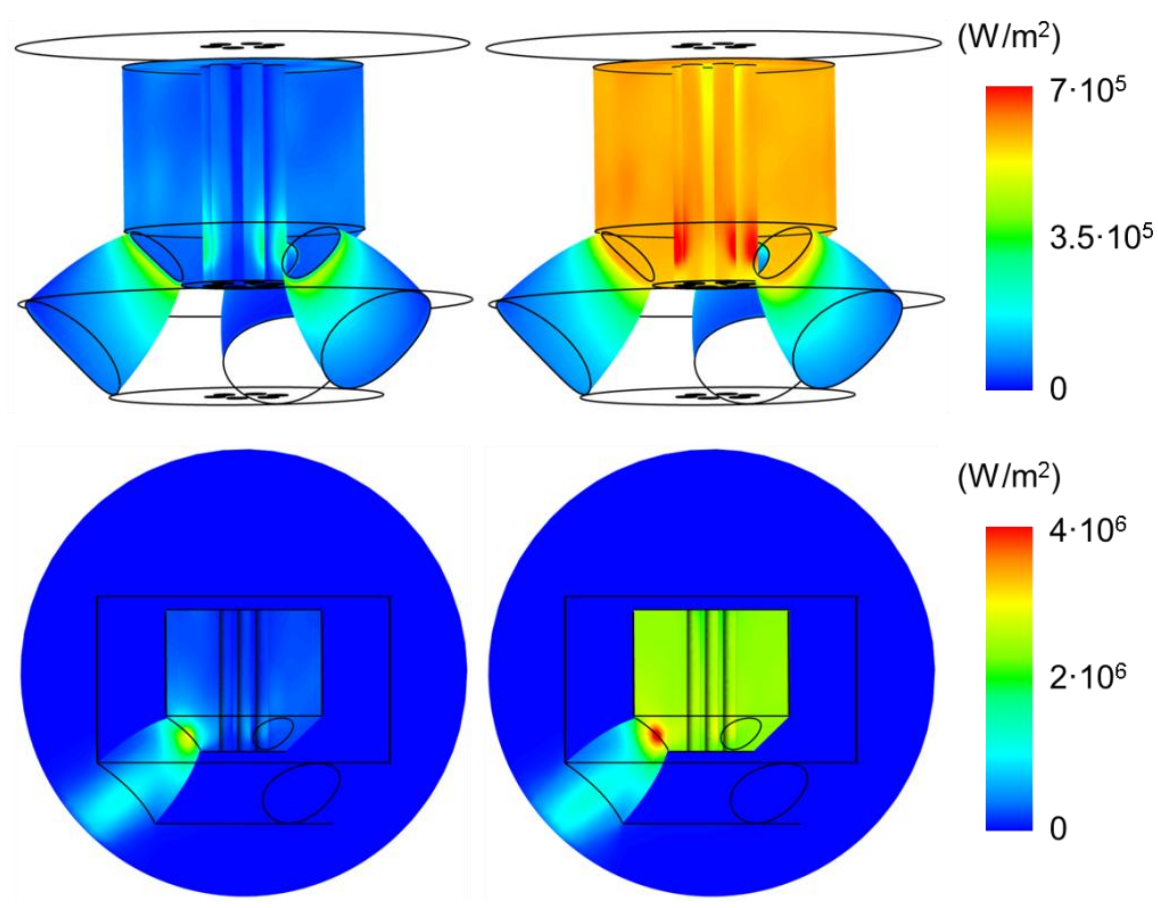

Figure 7. Surface incident (top) and incident (bottom) radiation profiles on the secondary concentrator, cavity and reactor tube walls accounting for a) direct solar radiation only and b) thermal re-radiation as well at conditions of Figure 6. 
a) Reflected radiation

b) Absorbed radiation
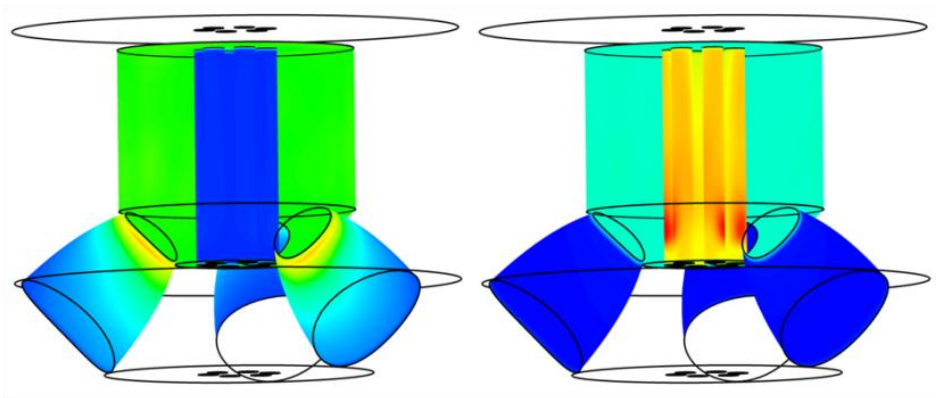

$\left(\mathrm{W} / \mathrm{m}^{2}\right)$

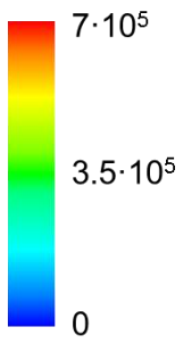

c) Radiative heat flux

d) Total heat flux

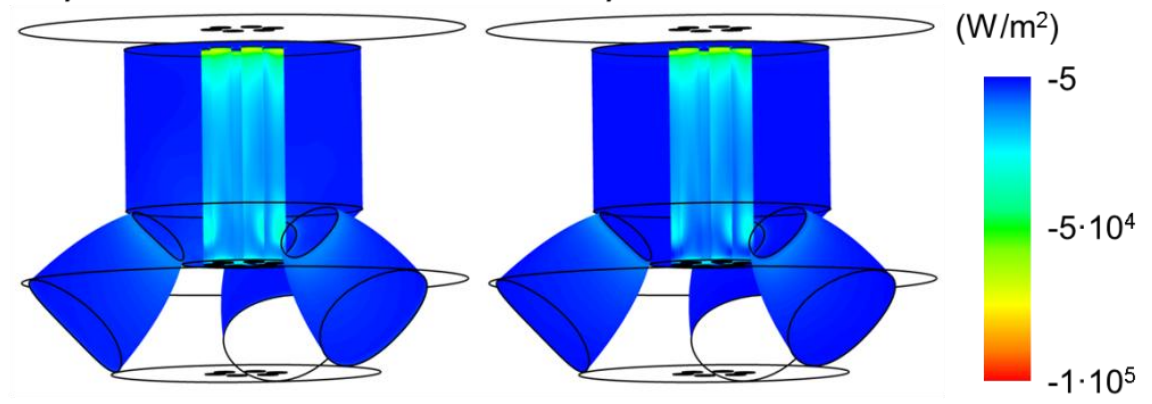

Figure 8. Profiles of a) reflected, b) absorbed, c) total radiation and d) total heat flux accounting for convection and conduction with reactor tube radius of $25 \mathrm{~cm}$ at conditions of Figure 6. In bottom row, negative values indicate flux into the visible surfaces. 


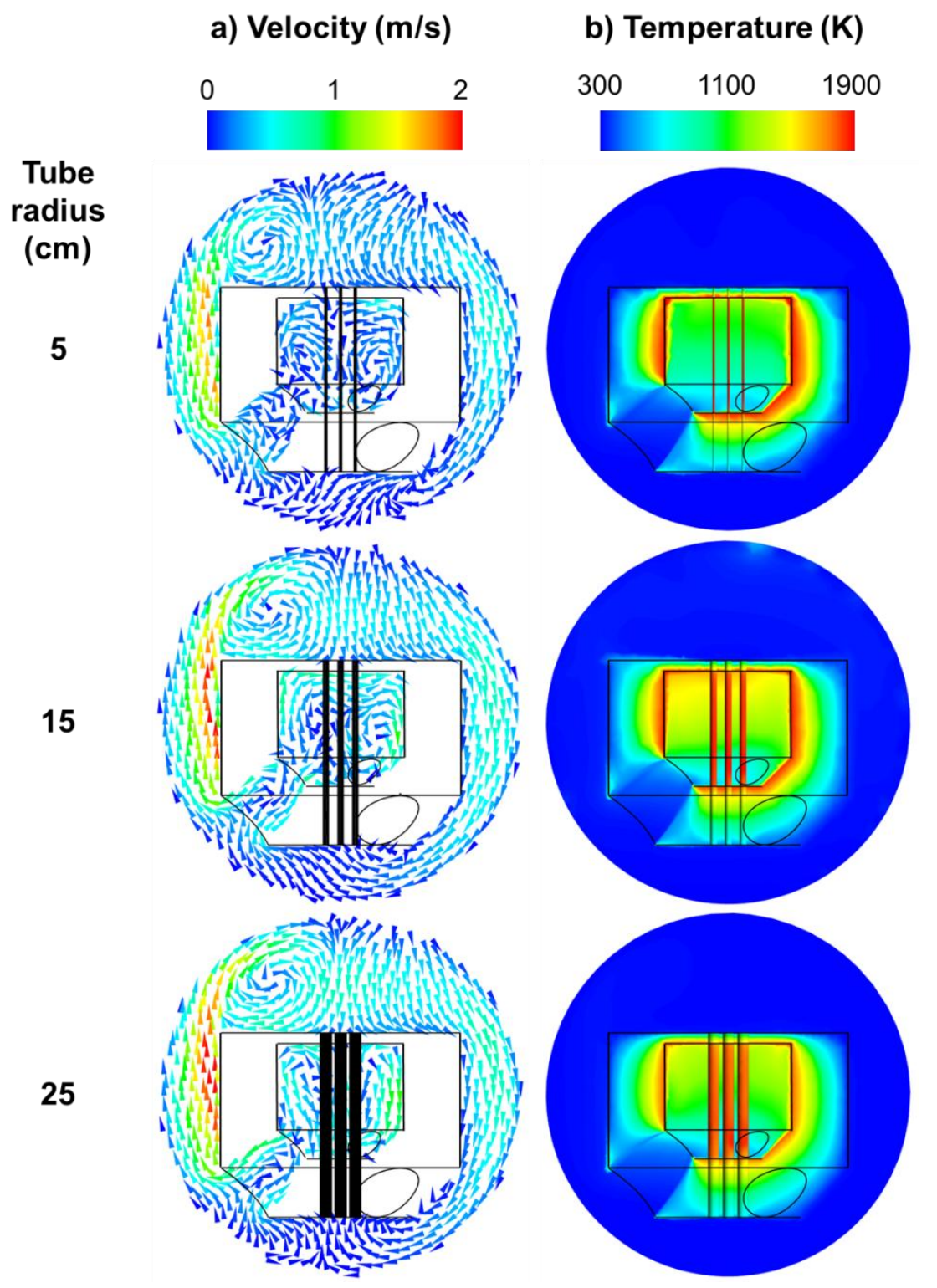

Figure 9. Simulated a) velocity vectors and b) temperature profiles at a cross-section of the solarthermal reactor for $\mathrm{SiC}$ reactor tube radii between $5-25 \mathrm{~cm}$ with constant ceria bed velocity of 1 $\mathrm{cm} / \mathrm{s}$. Fluid flow in the reactor is not affected significantly by the reactor tube size. However, slightly lower cavity wall temperatures are observed with increasing tube diameter due to larger amount of heat transferred through bigger available surface area. 


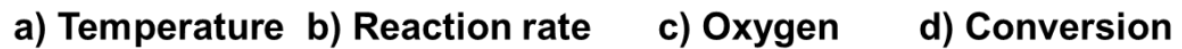 (K) $\quad\left(\mathrm{mol} \cdot \mathrm{m}^{-3} \cdot \mathrm{s}^{-1}\right) \quad$ mass fraction \\ (ס)}

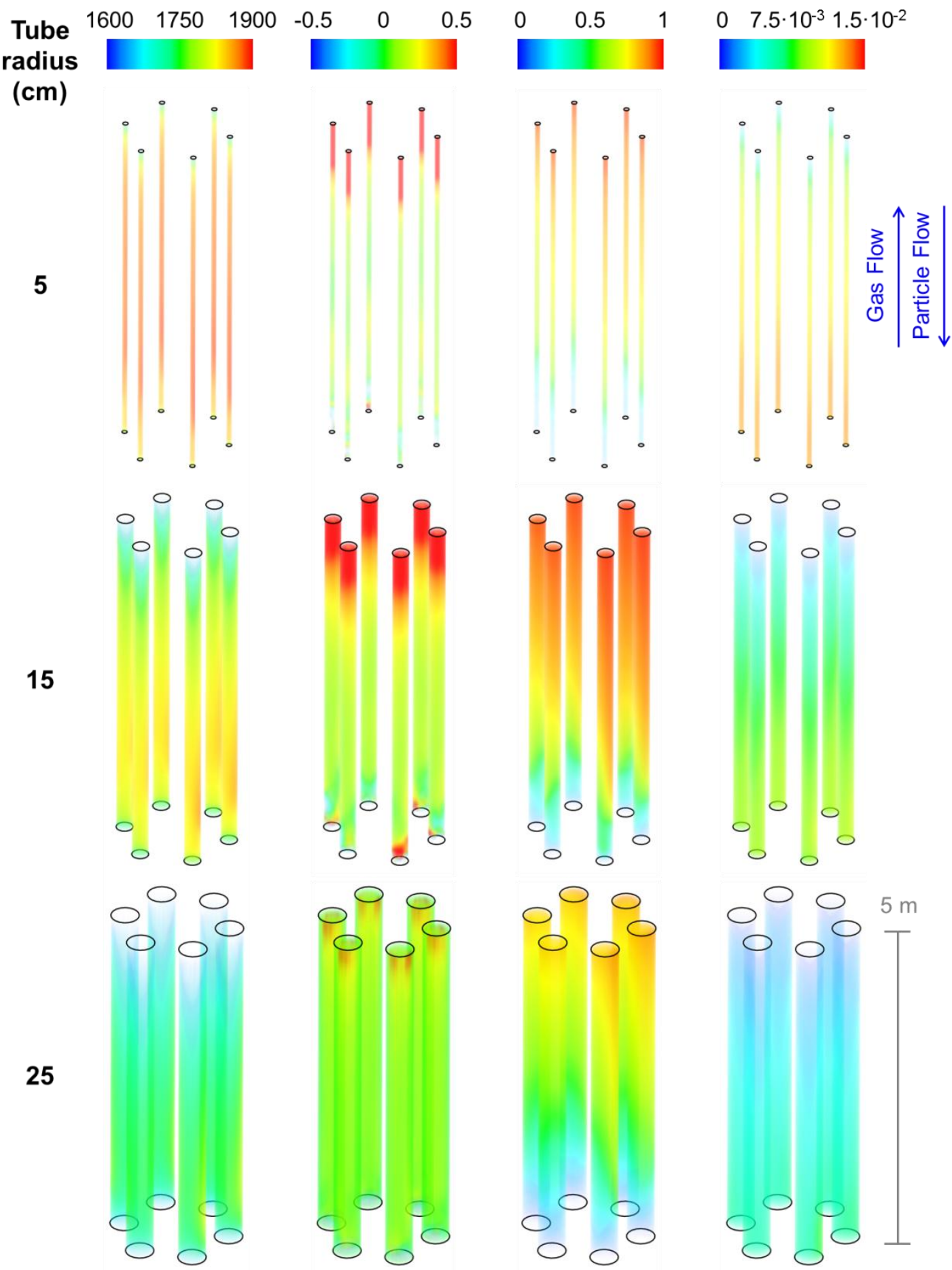

Figure 10. Volume renderings of model predicted a) temperature, b) $\mathrm{CeO}_{2}$ reaction rate, c) $\mathrm{O}_{2}$ mass fraction and d) $\mathrm{CeO}_{2}$ conversion for $\mathrm{SiC}$ reactor tube radii of 5, 15 and $25 \mathrm{~cm}$ with constant ceria bed velocity of $1 \mathrm{~cm} / \mathrm{s}$. 


\section{References}

Abanades, S., Charvin, P., Flamant, G., 2007. Design and simulation of a solar chemical reactor for the thermal reduction of metal oxides: Case study of zinc oxide dissociation. Chemical Engineering Science. 62, 6323-33.

ANSYS. 2015. Fluent 17.0 Theory Guide. ANSYS inc.

Bulfin, B., Lowe, A., Keogh, K., Murphy, B., Lübben, O., Krasnikov, S., Shvets, I., 2013. Analytical model of $\mathrm{CeO}_{2}$ oxidation and reduction. The Journal of Physical Chemistry $\mathrm{C}$. 117, 24129-37.

Chen, H., Chen, Y., Hsieh, H.-T., Siegel, N., 2006. Computational Fluid Dynamics Modeling of Gas-Particle Flow Within a Solid-Particle Solar Receiver. Journal of Solar Energy Engineering. 129, 160-70.

Chui, E., Raithby, G., 1993. Computation of radiant heat transfer on a nonorthogonal mesh using the finite-volume method. Numerical Heat Transfer. 23, 269-88.

DIPPR. 2005. "DIPPR Project 801-Full Version." In.: Design Institute for Physical Property Data/AIChE.

Furler, P. 2014. Solar Thermochemical $\mathrm{CO}_{2}$ and $\mathrm{H}_{2} \mathrm{O}$ Splitting via Ceria Redox Reactions, Diss., Eidgenössische Technische Hochschule ETH Zürich, Nr. 21864.

Furler, P., Scheffe, J.R., Steinfeld, A., 2012. Syngas production by simultaneous splitting of $\mathrm{H}_{2} \mathrm{O}$ and $\mathrm{CO}_{2}$ via ceria redox reactions in a high-temperature solar reactor. Energy \& Environmental Science. 5, 6098-103.

He, Y.L., Xiao, J., Cheng, Z.D., Tao, Y.B., 2011. A MCRT and FVM coupled simulation method for energy conversion process in parabolic trough solar collector. Renewable Energy. 36, 976-85.

Howell, J.R., 1998. The Monte Carlo method in radiative heat transfer. Journal of heat transfer. $120,547-60$.

Hughmark, G., 1967. Mass and heat transfer from rigid spheres. AIChE Journal. 13, 1219-21.

Joseph, D., Perez, P., El Hafi, M., Cuenot, B., 2009. Discrete ordinates and monte carlo methods for radiative transfer simulation applied to computational fluid dynamics combustion modeling. Journal of heat transfer. 131, 052701-09.

Knovel. 2008. 'Knovel Crticial Tables (2nd Edition)', Accessed 28.7.2016. http://app.knovel.com/hotlink/toc/id:kpKCTE000X/knovel-critical-tables/knovel-criticaltables.

Martinek, J., Bingham, C., Weimer, A.W., 2012a. Computational modeling and on-sun model validation for a multiple tube solar reactor with specularly reflective cavity walls. Part 1: Heat transfer model. Chemical Engineering Science. 81, 298-310.

Martinek, J., Bingham, C., Weimer, A.W., 2012b. Computational modeling of a multiple tube solar reactor with specularly reflective cavity walls. Part 2: Steam gasification of carbon. Chemical Engineering Science. 81, 285-97.

Martinek, J., Weimer, A.W., 2013a. Design considerations for a multiple tube solar reactor. Solar Energy. 90, 68-83.

Martinek, J., Weimer, A.W., 2013b. Evaluation of finite volume solutions for radiative heat transfer in a closed cavity solar receiver for high temperature solar thermal processes. International Journal of Heat and Mass Transfer. 58, 585-96.

Meier, A., 1999. A predictive CFD model for a falling particle receiver/reactor exposed to concentrated sunlight. Chemical Engineering Science. 54, 2899-905. 
Menter, F.R., 1994. Two-equation eddy-viscosity turbulence models for engineering applications. AIAA journal. 32, 1598-605.

Moghimi, M.A., Craig, K.J., Meyer, J.P., 2015. A novel computational approach to combine the optical and thermal modelling of Linear Fresnel Collectors using the finite volume method. Solar Energy. 116, 407-27.

Morrell, R. 1987. Handbook of properties of technical and engineering ceramics Part 2 (HMSO).

Muhich, C.L., Ehrhart, B.D., Al-Shankiti, I., Ward, B.J., Musgrave, C.B., Weimer, A.W., 2016. A review and perspective of efficient hydrogen generation via solar thermal water splitting. Wiley Interdisciplinary Reviews: Energy and Environment. 5, 261-87.

Munro, R., 1997. Material properties of a sintered $\alpha$-SiC. Journal of Physical and Chemical Reference Data. 26, 1195-203.

Murray, J.P., Steinfeld, A., Fletcher, E.A., 1995. Metals, nitrides, and carbides via solar carbothermal reduction of metal oxides. Energy. 20, 695-704.

Neuer, G., Jaroma-Weiland, G., 1998. Spectral and total emissivity of high-temperature materials. International Journal of Thermophysics. 19, 917-29.

Neumann, A., Witzke, A., Jones, S.A., Schmitt, G., 2002. Representative terrestrial solar brightness profiles. Journal of Solar Energy Engineering-Transactions of the Asme. 124, 198-204.

NIST. 2016a. 'Aluminium Oxide Material Properties', Accessed 28.7.2016. http://webbook.nist.gov/cgi/cbook.cgi?ID=C1344281\&Mask=2.

NIST. 2016b. 'NIST Structural Ceramics Database (SCD)', Accessed 28.7.2016. http://www.ceramics.nist.gov/srd/scd/Z00501.htm\#M1P16.

Özgümüş, T., Mobedi, M., Özkol, Ü., Nakayama, A., 2013. Thermal Dispersion in Porous Media-A Review on the Experimental Studies for Packed Beds. Applied Mechanics Reviews. 65, 031001-19.

Perkins, C., Weimer, A., 2007. Computational Fluid Dynamics Simulation of a Tubular Aerosol Reactor for Solar Thermal ZnO Decomposition. Journal of Solar Energy Engineering. 129, 391-404.

Piatkowski, N., Wieckert, C., Weimer, A.W., Steinfeld, A., 2011. Solar-driven gasification of carbonaceous feedstock - a review. Energy \& Environmental Science. 4, 73-82.

Ramanathan, K., Yen, S.H., Estalote, E.A., 1977. Total hemispherical emissivities of copper, aluminum, and silver. Applied optics. 16, 2810-17.

RATH. 2016. 'RATH KVS 184/400 Specification Datasheet', Accessed 28.7.2016. http://www.rath-usa.com/kvs_high.php.

Schaeffer, D.G., 1987. Instability in the evolution equations describing incompressible granular flow. Journal of differential equations. 66, 19-50.

Scheffe, J.R., Welte, M., Steinfeld, A., 2014. Thermal reduction of ceria within an aerosol reactor for $\mathrm{H}_{2} \mathrm{O}$ and $\mathrm{CO}_{2}$ splitting. Industrial \& Engineering Chemistry Research. 53, 2175-82.

Subramaniam, S., 2013. Lagrangian-Eulerian methods for multiphase flows. Progress in Energy and Combustion Science. 39, 215-45.

Syamlal, M., Rogers, W., O’Brien, T.J., 1993. MFIX documentation: Theory guide. National Energy Technology Laboratory, Department of Energy, Technical Note DOE/METC95/1013 and NTIS/DE95000031.

Vasquez, S., Ivanov, V. 2000. "A phase coupled method for solving multiphase problems on unstructured meshes." In Proceedings of ASME FEDSM'00: ASME 2000 fluids engineering division summer meeting, Boston, 1-6. 
Wendelin, T., Dobos, A., Lewandowski, A., 2013. SolTrace: A ray-tracing code for complex solar optical systems. NREL/TP-5500-59163.

Winston, R., Miñano, J.C., Benitez, P.G. 2005. Nonimaging optics (Academic Press).

Wirz, M., Roesle, M., Steinfeld, A., 2012. Three-dimensional optical and thermal numerical model of solar tubular receivers in parabolic trough concentrators. Journal of Solar Energy Engineering. 134, 0410121-9.

Yaws, C.L. 2006. Yaws handbook of thermodynamic properties for hydrocarbons and chemicals (Gulf Pub.).

Yaws, C.L. 2011. Yaws Handbook of Properties of the Chemical Elements (Knovel). 